\title{
VARGAS VILA, MÁS ALLÁ DE LA HIPÉRBOLE
}

\author{
POR \\ JuAN CARlos GonzÁlez Espitia \\ María A. SALGado \\ The University of North Carolina at Chapel Hill
}

Si hay alguien al que la etiqueta de heterodoxo vaya bien, ese es José María Vargas Vila (1860-1933), muy probablemente el autor colombiano más vendido en el período de entresiglos diecinueve al veinte. La meta del programa de escritura de Vargas Vila era hacer temblar los fundamentos tradicionales que él consideraba como rémoras para la necesaria igualdad y el progreso deseado de la sociedad latinoamericana.

La lista de los puntos de ataque del panfletario puede ser muy larga, pero un simple resumen demuestra con claridad por qué fue tan incómodo. Un blanco favorito de su invectiva fue la Iglesia Católica y sus representantes, desde el corrupto sacerdote del pueblo remoto hasta el papa con sus blancos ropajes en Roma. Vargas Vila denunció la intromisión de la institución eclesiástica en los asuntos de Estado de los países que experimentaban con nuevas formas de gobernabilidad de corte liberal y que buscaban implementar la división entre Iglesia y Estado, la educación laica, la libertad de culto, la abolición de la pena de muerte y la modernización de la infraestructura de comunicación. Parte de ese viraje liberal incluyó una revisión radical de los conceptos de familia y relaciones interpersonales que hasta entonces habían estado por fuera de los límites de lo que se podía discutir en un texto literario respetable: el ataque contra el matrimonio, la escritura y aceptación de las relaciones homosexuales, la discusión pública sobre las relaciones sexuales del clero, o la exploración del tema del incesto. En el ámbito de lo literario, Vargas Vila escribió a contrapelo de una literatura de proyectos positivos, de prosa tersa, de estilo amaestrado o de temas edificantes, pero eso no significó que su producción no estuviera imbuida de las aspiraciones de justicia y libertad que deseaba incitar en su público. Paradójicamente, Vargas Vila fue un intransigente que no podía soportar a los intolerantes y por esa razón desde el mismo inicio de su vida pública su vitalidad radicó en la capacidad para provocar opiniones divididas.

Los temas más importantes en su obra son vigentes aún hoy e incluyen la crítica del puritanismo fingido, la arremetida contra las dictaduras y los totalitarismos, la opinión divergente frente a los desarrollos políticos de su tiempo, la defensa radical del individualismo y el abordaje del tema de la sexualidad. El contenido de sus libros 
era con frecuencia escandaloso, tal y como puede esperarse de un tipo de escritura que buscaba hostigar el statu quo. En varias de sus novelas incluyó el uso del opio, cloral o morfina, al mismo tiempo que con alevosía atacó a aquellos que encontraban reposo en ideas globalizantes como la patria o la posibilidad de la avenencia entre facciones políticas. Algunos de sus personajes más controvertidos incluyen un narrador que defiende y recomienda el suicidio para aquellos que obedecen ciegamente las reglas sociales; un sacerdote leproso que engendra un hijo con su prima; o una mujer con bella alma de artista que debe vivir prisionera de un cuerpo contrahecho y es maltratada por el hombre que sólo está con ella por su riqueza. Semejante ímpetu en los ataques trajo sus consecuencias. Algunos de los gobernantes que sintieron las flechas pagaron a diaristas para que escribieran denuestos contra Vargas Vila en la prensa. La Iglesia Católica arremetió contra él desde los púlpitos y prohibió algunos de sus libros, pero no llegó a excomulgarlo, como se ha dicho varias veces sin razón. En varias instancias escritas se observa el regodeo de Vargas Vila en estos ataques que elevaban su bien cultivada aura de perseguido y aumentaban las ventas de su obra.

La técnica dominante en sus textos es aquella de la escritura fragmentada. Párrafos cortos, afirmaciones aforísticas, violación de las reglas tradicionales de puntuación, incorporación de extranjerismos y oraciones en otras lenguas, juegos de palabras, insultos, construcciones gramaticales latinizadas y juegos tipográficos son algunas de las estrategias utilizadas por Vargas Vila para sacudir al lector de su comodidad, esto es, de su deseo de ser entretenido en lugar de ser desafiado con ideas estimulantes a formar y reformar activamente su sociedad. Desdichadamente para la seriedad con que Vargas Vila acomete su misión revolucionaria, su estilo grandilocuente ha contribuido a que se haya extendido un juicio unánime entre los críticos, sea en son de burla o con apreciación más reposada, de que hay un tipo de escritura hiperbólica y altisonante que puede calificarse con el nombre de estilo vargasvilesco.

La controvertida figura de Vargas Vila sigue dando de qué hablar; a pesar del paso de los años su imagen no parece guardar el polvo de la historia. Es posible que la vigencia percibida del autor colombiano sea el resultado de la combinación de los dos términos con que acabamos de definirlo: figura y controversia. Por un lado, la capacidad de su escritura para producir reacciones polarizadas ha hecho de él una presencia recurrente y espectral -hoy, como hace cien años, hay quienes quieren poner a Vargas Vila en la caneca de la historia, del mismo modo que hay aquellos para quienes Vargas Vila tiene cualidades casi proféticas con respecto al destino político de los países latinoamericanos-. Por el otro, el que la escritura de Vargas Vila sólo lo sea si está unida a lo que su autor ha representado, la ha convertido en una propuesta de difícil definición en la que lo ficcional se funde con la percepción incompleta de lo real: una dinámica que termina por producir imágenes que rayan en lo mítico -hoy, como hace cien años, la historia de que el panfletista se rehusara a arrodillarse ante el papa León XIII, o aquella de que sus

Revista Iberoamericana, Vol. LXXXII, Núm. 254, Enero-Marzo 2016, 723-727 ISSN 0034-9631 (Impreso)

ISSN 2154-4794 (Electrónico) 
manos habían sido quemadas con vitriolo por una amante celosa, son lugares comunes cuyo origen es claramente literario-. La tensión entre obra y autor, entre conseja y textualidad, entre admiración acrítica y odio enconado nos deja, a ciento cincuenta años de su nacimiento, con un Vargas Vila inusitadamente vivo pero al mismo tiempo con un Vargas Vila infortunadamente nebuloso.

Esta tensión ambigua se encuentra en el trasfondo de las aproximaciones críticas a la obra y persona del "Divino". Rafael Maya (1897-1980) comparó la presencia de Vargas Vila con una estatua en medio de un bosque. Para el crítico esa estatua, desde lejos, medio oculta entre el follaje y las sombras, parecía fuerte, marmórea, dominante. Pero cuando el transeúnte se acercaba a ella y desbrozaba el ramaje se encontraba con un busto simple, puesto sobre una base tosca de material ordinario. La imagen es apropiada en el caso de Vargas Vila, pero su corolario no puede ser, como muchos afirman, que su persona y obra deban ser puestas a un lado para dedicarse a los autores de supuestas verdaderas proporciones escultóricas: José Asunción Silva o Jorge Isaacs para el caso colombiano, y José Martí, Rubén Darío o José Enrique Rodó en el marco latinoamericano.

Siguiendo con la misma imagen de la estatua entre el follaje, el asunto es que la estrategia de aproximación del transeúnte no puede ser la misma que la del crítico literario o la del lector que lee leyendo y no de oídas. El crítico y el lector serio -que son o deben ser una y la misma cosa- no se acerca a la estatua despejando el follaje a mandobles. Al contrario, aparta cada rama y apunta sus particularidades, reflexiona sobre las razones por las cuales la estatua se ve imponente desde lejos y deleznable desde cerca, arriesga interpretaciones sobre por qué tantos han usado esa estatua perdida en el bosque como referente político y literario. Y sobre todo, se pregunta por qué, a pesar del paso del tiempo, de la lluvia que le ha caído y de las piedras que le han tirado, la estatua sigue en pie.

El inicio de la labor juiciosa de estudio de la obra de Vargas Vila se ha hecho difícil hasta el momento por la falta de acceso al gran número de obras que publicó. Sólo la “obra definitiva" publicada por Ramón Sopena en Barcelona en vida del autor rebasa los cincuenta títulos, a lo que se suma lo publicado anterior o posteriormente por Maucci, Americana, Bouret, Sanz Calleja, Biblioteca Nueva y Bauzá. Sólo la evaluación seria de la producción de Vargas Vila ha de fomentar el estudio justo de esta piedra angular del pensamiento latinoamericano, no necesariamente para llegar a la conclusión de que su obra tiene proporciones escultóricas, sino más bien para entenderla como punto de toque que conecta los idearios políticos y literarios postindependentistas con los cambios experimentados por Latinoamérica en la primera mitad del siglo XX. Un lugar por el que se puede iniciar esa valoración es la lectura de la obra completa del autor que se encuentra ahora disponible gratuitamente en formato digital, gracias a un esfuerzo de la Universidad de Carolina del Norte en Estados Unidos, a través de la página www. vargasvila.org

Revista Iberoamericana, Vol. LXXXII, Núm. 254, Enero-Marzo 2016, 723-727 ISSN 0034-9631 (Impreso)

ISSN 2154-4794 (Electrónico) 
Algunos números y varias cuentas pendientes. Más de ciento cincuenta y tres años han pasado desde el nacimiento de José María Vargas Vila, y más de ochenta desde que murió. Durante el transcurso de los últimos ciento treinta años, desde cuando Vargas Vila se inició en el camino del escándalo con la publicación de una acusación de sodomía y pederastia contra el sacerdote jesuita Tomás Escobar en el periódico La Actualidad de Bogotá, las opiniones críticas sobre su obra y su persona han sido repetidas, pero no necesariamente novedosas. Una de esas repeticiones críticas es que Vargas Vila escribió muchísimos libros. Una cuenta física de sus libros que hemos hecho recientemente sobrepasa los ochenta títulos. Las ediciones oficiales y no oficiales de varias de sus obras son prácticamente incontables porque sus libros han sido publicados como por ensalmo de piratería. Un motor electrónico de búsqueda bibliográfica arroja más de 1.580 títulos en los que Vargas Vila aparece relacionado como autor; otro motor de búsqueda general en la internet arroja medio millón de resultados cuando se escribe su nombre completo. Existen ediciones de novelas de Vargas Vila publicadas en los más disímiles países, desde Argentina hasta Ecuador, desde México hasta España, desde Estados Unidos hasta Alemania, pasando por Venezuela, República Dominicana, Italia, Brasil, Ecuador y Francia. Con todos estos números que dan cuenta del alcance de su obra, Vargas Vila es un autor reconocido, pero desconocido. El estado de los estudios sobre Vargas Vila ha cambiado en los últimos ochenta años, pero aún tiene lastres de opiniones del ayer. A la desmesura hiperbólica de su estilo y de su aproximación temática la crítica ha respondido con igual desmesura hiperbólica. Ya es lugar común oír el retumbar de los odios intensos y los intensos amores de aquellos que siguen ciegamente a Vargas Vila y aquellos que a ciegas lo persiguen. El verbo “oír” tiene aquí mucha importancia semántica porque Vargas Vila ha sido uno de esos autores que muchos lectores y críticos han leído de oídas, ha sido citado y vuelto a citar en sus fragmentos de pirotecnia, pero apenas empiezan a aparecer los estudios que se toman el trabajo de ir más allá de los ocho o diez títulos trillados. Esto significa que hemos hecho crítica sobre apenas el diez por ciento de su obra y eso habla muy mal de nuestras matemáticas o de nuestra habilidad para rendir cuentas. Sin embargo, la idea de que a la desmesura hiperbólica de Vargas Vila se le oponga la desmesura crítica no significa que la ley del Talión, diente por diente, haya sido una fórmula productiva. La prueba de este camino errado es que Vargas Vila, con hipérbole y todo, o precisamente por lo hiperbólico, mantiene su poder de producir reacciones de todos los tipos, mientras que nosotros seguimos repitiendo las mismas reacciones. Atañe a la literatura la hipérbole porque es una de las herramientas de su caja. No obstante, la aproximación hiperbólica de algunos críticos, que es diferente de una aproximación crítica apasionada, ha resultado en el caso de Vargas Vila una herramienta cortopunzante, pero que en últimas ni punza ni corta.

Vargas Vila, ciento cincuenta años después, sigue produciendo reacciones mientras que, a decir verdad, mucha de nuestra crítica está guardando polvo en los anaqueles.

Revista Iberoamericana, Vol. LXXXII, Núm. 254, Enero-Marzo 2016, 723-727 ISSN 0034-9631 (Impreso)

ISSN 2154-4794 (Electrónico) 
La defensa que hacemos de nuestras tristes matemáticas críticas es que Vargas Vila es repetitivo, o peor aún, que su obra es de mala calidad, una afirmación a la que llegamos contradictoriamente después de evaluar unas pocas obras que podemos contar sobradamente con los dedos de las manos. Parece entonces que hace falta leer más y mejor a Vargas Vila, forjar una herramienta que corte y que punce en el tejido de su obra, pero con mayor certeza, mejor dicho, con mayor justicia. Leer críticamente, quizás por primera vez, sin prevenciones positivas o negativas, los textos menos conocidos de su producción. El resultado de este tipo de labor mesurada y responsable será muy posiblemente uno que nos enseñe a Vargas Vila como productor literario, no como divino o como humano, para usar la que es ya una fórmula para referirse a él. En otras palabras, es hora de que dejemos el lujo de la hipérbole sólo para Vargas Vila.

Los ensayos que conforman este número de Revista Iberoamericana representan diferentes tipos de aproximación crítica a la producción de Vargas Vila. El ensayo de José Luis Díaz Granados ofrece una mirada general sobre la obra del autor y juzga su aporte literario o político como poco relevante en el ámbito latinoamericano. Los ensayos de María A. Salgado, William Clary y José M. García Sánchez, trazan temas o figuras bien definidos en varias obras del colombiano de manera sistemática y rigurosa, y logran el objetivo de revelar nuevas facetas en textos clásicos como Los divinos y los humanos y La muerte del cóndor o en obras menos referenciadas como las de la serie La Novela Corta. Por el mismo camino, los trabajos de Hugo Hernán Giraldo y Juan Carlos González Espitia reposicionan la labor de Vargas Vila como intelectual y como referente del Modernismo iberoamericano. Un tercer grupo, iniciado por el ensayo de Consuelo Triviño Anzola, quien revela el proceso de Vargas Vila de autor de novelas a personaje de ficción en su novela La semilla de la ira (2008), y continuado por Kevin Guerrieri y Fernando Díaz Ruiz, estudia versiones y revisiones ficcionales de la figura del colombiano que muestran las maneras en que el autor ha sido renarrativizado y vuelto a catapultar a las nuevas generaciones. Del mismo modo que el significado de la obra de Vargas Vila es vacilante por la imposibilidad de ubicarla como estatua marmórea o como busto sobre una base de ladrillo burdo, estos estudios trazan caminos plurivalentes de aproximación, y además de indicar el estado de la crítica sobre Vargas Vila revelan puntos de partida para nuevas rutas de evaluación de su obra.

La idea de este proyecto fue generada por María del Pilar Melgarejo Acosta, a quien agradecemos los primeros pasos y la intensa labor de revisión inicial de los ensayos. Agradecemos también a Juan Duchesne y al equipo de la Revista Iberoamericana por su apoyo para llevar a buen lugar los propósitos de todos los que hemos estado conectados con este esfuerzo.

\section{REFERENCIA ELECTRÓNICA}

http://www2.lib.unc.edu/wilson/rbc/vargasvila/index.html

Revista Iberoamericana, Vol. LXXXII, Núm. 254, Enero-Marzo 2016, 723-727 ISSN 0034-9631 (Impreso)

ISSN 2154-4794 (Electrónico) 
